\title{
Capacidade vegetativa e trocas gasosas em mudas de Pereskia aculeata Plum em diferentes substratos
}

Vegetative capacity and gas exchange in Pereskia aculeata Plum seedlings in different substrates

\author{
C. C. Santos ${ }^{1 *}$; A. Goelzer ${ }^{2}$; J. M. Silverio ${ }^{1}$; S. P. Q. Scalon ${ }^{1}$; N. A. Heredia \\ Zárate $^{1}$; M. C. Vieira ${ }^{1}$ \\ ${ }^{1}$ Faculdade de Ciências Agrárias, Universidade Federal da Grande Dourados (UFGD), 79804-970, Dourados-Mato \\ Grosso do Sul, Brasil \\ ${ }^{2}$ Departamento de Biotecnologia Vegetal, Universidade Federal de Lavras (UFLA), 37200-000, Lavras-Minas Gerais, \\ Brasil \\ *cleber_frs@yahoo.com.br
}

(Recebido em 22 de julho de 2019; aceito em 26 de novembro de 2019)

\begin{abstract}
Pereskia aculeata Plum. é uma planta alimentícia não convencional de interesse agromedicinal. Todavia, são poucas informações técnicas referentes aos fatores que podem influenciar sua propagação, tal como a escolha do substrato. Assim, objetivou-se avaliar o efeito de diferentes substratos na capacidade vegetativa e fotossintética em mudas de $P$. aculeata. O experimento foi desenvolvido sob viveiro com $50 \%$ de sombreamento, avaliando-se quatro substratos: $S_{1}$ ) Latossolo Vermelho Distroférrico (LVd), $\left.S_{2}\right)$ LVd + Tropstrato $\left.^{\circledR}(1: 1, \mathrm{v} / \mathrm{v}), \mathrm{S}_{3}\right) \mathrm{LVd}+$ areia $(1: 1, \mathrm{v} / \mathrm{v})$, e $\left.\mathrm{S}_{4}\right) \mathrm{LVd}+$ cama de frango semidecomposta base casca de $\operatorname{arroz}(3: 1, \mathrm{v} / \mathrm{v})$. A propagação foi realizada utilizando estacas de $20 \mathrm{~cm}$ da porção mediana do ramo, e um par de folhas no ápice da estaca, sendo feito o enterrio $1 / 3$ nos substratos correspondentes. A partir do $21^{\circ}$ dia, semanalmente, até o $49^{\circ}$ dia após enterrio (DAE), contabilizou-se a porcentagem de brotação e número de brotos, e aos 60 e 65 dias, avaliaram-se as características fisiológicas e vegetativas, respectivamente. Constatou-se maior brotação $(92 \%)$ e número de brotos $(3,26)$ aos 49 DAE, e com maiores indicadores de brotação e massa fresca de folhas nas mudas produzidas em LVd + Tropstrato ${ }^{\circledR} \mathrm{e} \mathrm{LVd} \mathrm{+} \mathrm{cama} \mathrm{de} \mathrm{frango.} \mathrm{As}$ maiores trocas gasosas e eficiência de carboxilação da Rubisco ocorreram nas mudas produzidas em LVd + cama de frango. Assim, o Tropstrato ${ }^{\circledR}$ e a cama de frango podem ser utilizados na formulação de substratos para $P$. aculeata, por favorecer maior capacidade vegetativa e fotossintética das mudas.

Palavras-chave: Ora-pro-nóbis, cama de frango, atividade fotossintética.
\end{abstract}

Pereskia aculeata Plum. is an unconventional food plant of agromedicinal interest. However, technical information is incipient, regarding the factors that may influence its propagation and photosynthetic capacity, such as the choice of substrate in the early stage of initial. Thus, the aim was to know the effect of different substrates on vegetative and photosynthetic capacity in $P$. aculeata. The experiment was carried out under $50 \%$ shading conditions, with four substrates being evaluated: $\mathrm{S}_{1}$ ) Dystroferric Red Latosol (DRL), $\mathrm{S}_{2}$ ) DRL + Tropstrato $\left.{ }^{\circledR}(1: 1, \mathrm{v} / \mathrm{v}), \mathrm{S}_{3}\right)$ DRL + sand $(1: 1, \mathrm{v} / \mathrm{v})$, and $\left.\mathrm{S}_{4}\right)$ DRL + semi-composite poultry manure base rice husk $(3: 1, \mathrm{v} / \mathrm{v})$. The propagation was carried out using cuttings of $20 \mathrm{~cm}$ of the middle portion of the branch, and a pair of leaves at the apex of the stake. From $21^{\circ}$ to $49^{\circ}$ day after enterrial (DAE), the sprouting percentage and number of shoots were counted, and at 60 and 65 days, the physiological and vegetative characteristics were evaluated. It was observed higher sprouting (92\%) and number of sprouts (3.26) at 49 DAE, and with higher sprout indicators and fresh mass in DRL + Tropstrato ${ }^{\circledR}$ and DRL + poultry manure plants. The higher gas exchanges and carboxylation efficiency of Rubisco were on plants produced in DRL + poultry manure. Thus, the Tropstrato ${ }^{\circledR}$ and the poultry manure can be used in the formulation of substrates for $P$. aculeata, since they greater vegetative and photosynthetic capacity of the seedlings. Keywords: "Ora-pro-nóbis", poultry manure, photosynthetic activity.

\section{INTRODUÇÃO}

Ora-pro-nóbis (Pereskia aculeata Plum.) pertence à família Cactaceae, considerada uma hortaliça enquadra-se no grupo das plantas alimentícias não convencionais - PANC's [1]. A espécie apresenta potencial alimentício, medicinal e ornamental, favorecendo sua exploração econômica, principalmente por agricultores familiares.

As folhas da espécie apresentam alto conteúdo proteico e de fibras [2, 3], tornando-se importante fonte na alimentação humana por meio de sua inserção no preparo de sopas, refogados, omeletes, 
saladas, biscoito doce e torta salgada; ainda é usada na alimentação animal [3, 4, 5, 6]. Além disso, seus frutos frescos podem ser utilizados no preparo de geleias, doces ou sucos [7].

Quanto aos aspectos medicinais, as folhas são utilizadas como emoliente, e seus frutos são como expectorante e antissifilítico, sem relatos de toxicidade no abrandamento dos processos inflamatórios e na recuperação da pele em casos de queimadura [8,9]. Do ponto de vista ornamental, a planta é utilizada como cercas vivas em função de seu rápido crescimento vegetativo e presença de acúleos.

Considerando a importância agromedicinal da espécie faz-se necessário seu cultivo almejando estabelecimento de campos de produção de bases sustentáveis. A propagação da espécie é feita vegetativamente devido principalmente à dificuldade de obtenção de sementes e baixo percentual de germinação, utilizando-se partes dos órgãos da planta mãe, para obtenção de mudas. Dentre as técnicas utilizadas, a estaquia possibilita a uniformidade e qualidade das mudas [10], além de ser de baixo custo e fácil execução.

Todavia, o sucesso da produção de mudas não depende apenas dos aspectos do material vegetal coletado. Para obtenção de mudas vigorosas, um dos fatores determinados é a escolha do substrato. O substrato deve apresentar características químicas, físicas e microbiológicas adequadas [11], que assegurem a formação e qualidade das mudas. Existem diversos substratos comerciais disponíveis no mercado, mas quando em elevadas quantidades, pode ser um fator oneroso ao produtor rural e/ou viveirista. Assim, é necessário estudar combinações de materiais de fácil disponibilidade na região de interesse que possam reduzir custos de produção, bem como propiciar condições adequadas na fase de viveiro para a espécie a ser produzida.

$\mathrm{Na}$ formulação de substratos, diversos materiais podem ser utilizados, tais como areia, casca de Pinus sp., casca de arroz carbonizada, esterco bovino, lodo de esgoto, húmus de minhoca, composto orgânico, entre outros. A cama de frango é um resíduo orgânico disponível nas regiões produtoras podendo ser utilizada na formulação de substratos e/ou solo de cultivo, pois melhora a fertilidade do substrato, capacidade de retenção de água, aumento da microbiota, contribuindo na ciclagem biogeoquímica [12], na disponibilidade de nutrientes e crescimento das plantas. Em estudo realizado por Lima et al. (2006) [12], na produção de mudas de Ricinus communis L., os autores verificaram que substrato (solo) com adição de cama de frango, favoreceu os indicadores de crescimento e qualidade das mudas. Entretanto, não se conhece os efeitos desse material como componente de substrato para $P$. aculeata.

Outro material utilizado é a areia, mas cabe ressaltar que as respostas morfofisiológicas e qualidade das mudas variam de acordo a espécie. Assim, considerando a hipótese de que as mudas da espécie propagadas vegetativamente podem apresentar respostas diferenciadas aos substratos, objetivou-se com este trabalho avaliar o efeito de diferentes substratos na capacidade vegetativa e fotossintética de mudas de P. aculeata propagadas por estaquia caulinar.

\section{MATERIAL E MÉTODOS}

O experimento foi realizado no período de junho a agosto de 2017, no Horto de Plantas

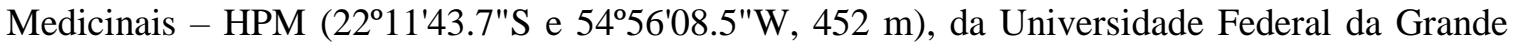
Dourados - UFGD, Dourados - MS, Brasil. As condições foram de viveiro, com tela superior de coloração preta com retenção de $50 \%$ do fluxo de radiação solar, com densidade de fluxo de fótons de $684,58 \mu \mathrm{mol} \mathrm{m} \mathrm{m}^{-2} \mathrm{~s}^{-1}$, concentração de $\mathrm{CO}_{2}$ atmosférico de $388,37 \mathrm{ppm} \mathrm{e} 23^{\circ} \mathrm{C}$. O clima da região é classificado como Am (Clima tropical de monções) [13]. O manejo da irrigação foi realizado diariamente com dois turnos de rega.

Os aspectos vegetativos e fisiológicos das mudas de $P$. aculeata foram avaliados em função de quatros substratos: [S1) Latossolo Vermelho Distroférrico - controle (LVd), S2) LVd + substrato comercial $\left(\right.$ Tropstrato $\left.\left.^{\circledR}\right)(1: 1, \mathrm{v} / \mathrm{v}), \mathrm{S} 3\right) \mathrm{LVd}+$ areia $(1: 1, \mathrm{v} / \mathrm{v})$, e S4) $\mathrm{LVd}+$ cama de frango semidecomposta base casca de arroz $(3: 1, \mathrm{v} / \mathrm{v})]$. O delineamento experimental utilizado foi em blocos ao acaso, com quatro tratamentos (substratos) e quatro repetições, em que a unidade experimental constituiu-se de dez sacos de polietileno de $500 \mathrm{~mL}$, com uma estaca cada. Os dados 
tomados ao longo do período de manutenção na casa de vegetação foram analisados em parcelas subdividas no tempo (Split-plot).

A areia foi do tipo fina e lavada; o Latossolo Vermelho Distroférrico, de textura argilosa [14] e o substrato comercial (Tropstrato ${ }^{\circledR}$ ) em sua composição contém casca de Pinus sp., fibra de coco, PG Mix 14.16.18, nitrato de potássio e superfosfato simples, em que seus atributos químicos encontram-se na Tabela 1, de acordo com metodologia de Silva (2009) [15] e dados do fabricante, respectivamente.

Tabela 1 - Atributos químicos do Latossolo Vermelho Distroférrico e substrato comercial (Tropstrato ${ }^{\circledR}$ ) utilizados na formulação dos substratos.

\begin{tabular}{cccccccccc}
\hline $\mathbf{p H}$ & $\mathbf{P}$ & $\mathbf{K}$ & $\mathbf{C a}$ & $\mathbf{M g}$ & $\mathbf{A l}$ & $\mathbf{H}+\mathbf{A l}$ & $\mathbf{S B}$ & $\mathbf{C T C}$ & $\mathbf{V}$ \\
\hline $\mathrm{CaCl}_{2}$ & $\mathrm{mg} \mathrm{dm}^{-3}$ & \multicolumn{7}{c}{$\mathrm{cmol}_{\mathrm{c}} \mathrm{dm}^{-3}$} \\
\hline \multicolumn{7}{c}{ Latossolo Vermelho Distroférrico (LVd) } \\
\hline 6,20 & 3,90 & 4,00 & 6,70 & 2,80 & 1,20 & 29,90 & 12,90 & 42,40 & 60,5 \\
\hline \multicolumn{7}{c}{ Tropstrato $^{\circledR}$} \\
\hline 5,75 & 65,70 & 1,60 & 23,80 & 12,40 & 0,00 & 4,20 & 37,80 & 42,10 & 89,8 \\
\hline
\end{tabular}

A cama de frango semidecomposta foi proveniente de aviário da região Centro-Oeste, com seguintes atributos químicos $\left(\mathrm{g} \mathrm{kg}^{-1}\right): \mathrm{N}=23,90 ; \mathrm{P}=15,36 ; \mathrm{K}=20,00 ; \mathrm{Ca}=19,15 ; \mathrm{Mg}=6,95 ; \mathrm{S}=$ 18,65; $\mathrm{C}$ (carbono) $=260$; matéria orgânica $=447,00$; relação $\mathrm{C} / \mathrm{N}=10,87$; umidade $=11 \%$ e pH em $\mathrm{CaCl}_{2}=7,50$.

Para desenvolvimento do estudo, a espécie foi identificada e uma exsicata está depositada no Herbário, da UFGD, sob registro ${ }^{\circ}$ 5226. As estacas com diâmetro médio de 3,0 mm utilizadas foram coletadas da porção mediana de ramos jovens de plantas matrizes localizadas no HPM, no período matutino, utilizando-se tesoura de poda, sendo as bases imersas recipiente com água visando evitar a desidratação do tecido vegetal e/ou oxidação do nó basal. As estacas foram preparadas com corte da base e do ápice em bisel com comprimento de $20 \mathrm{~cm}$, e um par de folhas completo no ápice.

Os substratos com as combinações e proporções correspondentes foram colocados em sacos plásticos com capacidade de $500 \mathrm{~mL}$. As estacas tiveram $1 / 3$ do comprimento enterrados no substrato.

Durante o período experimental foram realizadas irrigações diárias utilizando-se regadores visando manter $70 \%$ da capacidade de campo de todos os substratos. Não houve incidência de pragas e de doenças.

Após o surgimento da primeira brotação, o que ocorreu, ao $21^{\circ}$ dia após enterrio (DAE) das estacas, realizou-se a contagem de porcentagem de brotação das estacas (brotos com $2 \mathrm{~cm}$ ), utilizando-se a fórmula adaptada de Maguire (1946) [16] (Brotação= $\mathrm{E}_{\mathrm{b}} / \mathrm{E}_{\mathrm{i}}$ x 100), em que: $\mathrm{E}_{\mathrm{b}}=$ número de estacas da parcela que tinham brotações e $\mathrm{E}_{\mathrm{i}}=$ número de estacas implantadas por parcela. A contagem das estacas com brotações foi realizada até aos 49 DAE, em intervalos de 7 dias, em função da estabilidade da emissão de brotos após esse período.

Aos 60 DAE, escolheram-se quatro mudas de forma aleatória, e realizou-se a quantificação dos aspectos fotossintéticos das mudas. A tomada de dados foi feita no período da manhã ( $08 \mathrm{~h}$ às $10 \mathrm{~h}$ ) em folhas totalmente expandidas das brotações, localizadas no terço médio. Avaliou-se a taxa de assimilação de $\mathrm{CO}_{2}$ (fotossíntese) $A$, concentração intercelular de $\mathrm{CO}_{2}-C_{\mathrm{i}}$, condutância estomática - gs e transpiração foliar - $E$, utilizando-se medidor de fotossíntese portátil (IRGA Infra Red Gas Analyzer). Calcularam-se a eficiência do uso da água $W U E(A / E)$ e instantânea de carboxilação da Rubisco $-A / C_{\mathrm{i}}$. Logo após, determinou-se o índice de clorofila, utilizando clorofilômetro portátil SPAD (Soil Plant Analyzer Development) (Konica Minolta SPAD 502).

Decorridos 65 DAE, as mudas foram retiradas inteiras dos recipientes, lavadas e avaliadas quanto ao comprimento das raízes, com régua graduada em $\mathrm{mm}$; número de brotos, folhas, comprimento da maior raiz e enraizamento das estacas (emissão de raízes com no mínimo $2 \mathrm{~cm}$ ). Em seguida, determinaram-se as áreas foliar e radicular das mudas, com integrador de área (LICOR, Modelo 3100 C; Nebraska, USA). Considerando o fato de que a parte de interesse 
agromedicinal são as folhas in natura, optou-se avaliar apenas as massas frescas da parte aérea (folhas) e raízes, pesando o material em balança de precisão milesimal $(0,0001 \mathrm{~g})$.

Os dados relacionados a brotação foram transformados em $\sqrt{ }(x+0,5)$ para normalização, e quando significativos foram apresentados os valores reais. Os dados obtidos foram submetidos à análise de variância (ANOVA), e quando detectou-se significância pelo teste $\mathrm{F}$, as médias foram comparadas pelo teste de Tukey $(\mathrm{p} \leq 0,05)$. Os dados analisados em parcelas subdividas no tempo foram submetidos ao teste $\mathrm{F}$, e à análise de regressão (significância dos modelos matemáticos) $(\mathrm{p} \leq 0,05)$. Todas as análises estatísticas foram realizadas com o software SISVAR [17].

\section{RESULTADOS E DISCUSSÃO}

A brotação e número de brotos foram influenciados pelas épocas de avaliação e substratos isoladamente. A maior porcentagem de brotação e número de brotos apresentaram ajuste quadrático com maiores máximas de 92,3\% de brotação e 3,26 brotos/estaca, aos 46 e 49 dias após o enterrio das estacas (Figura 1A e 1C, respectivamente). No que concerne aos substratos, essas características apresentaram maiores resultados quando produzidas em LVd + Tropstrato $^{\circledR}$ (Figuras 1B e 1D), ainda que estatisticamente não sejam diferentes do substrato LVd + cama de frango, superando em $57,7 \%$ e $73,3 \%$, quando comparados aos menores valores.
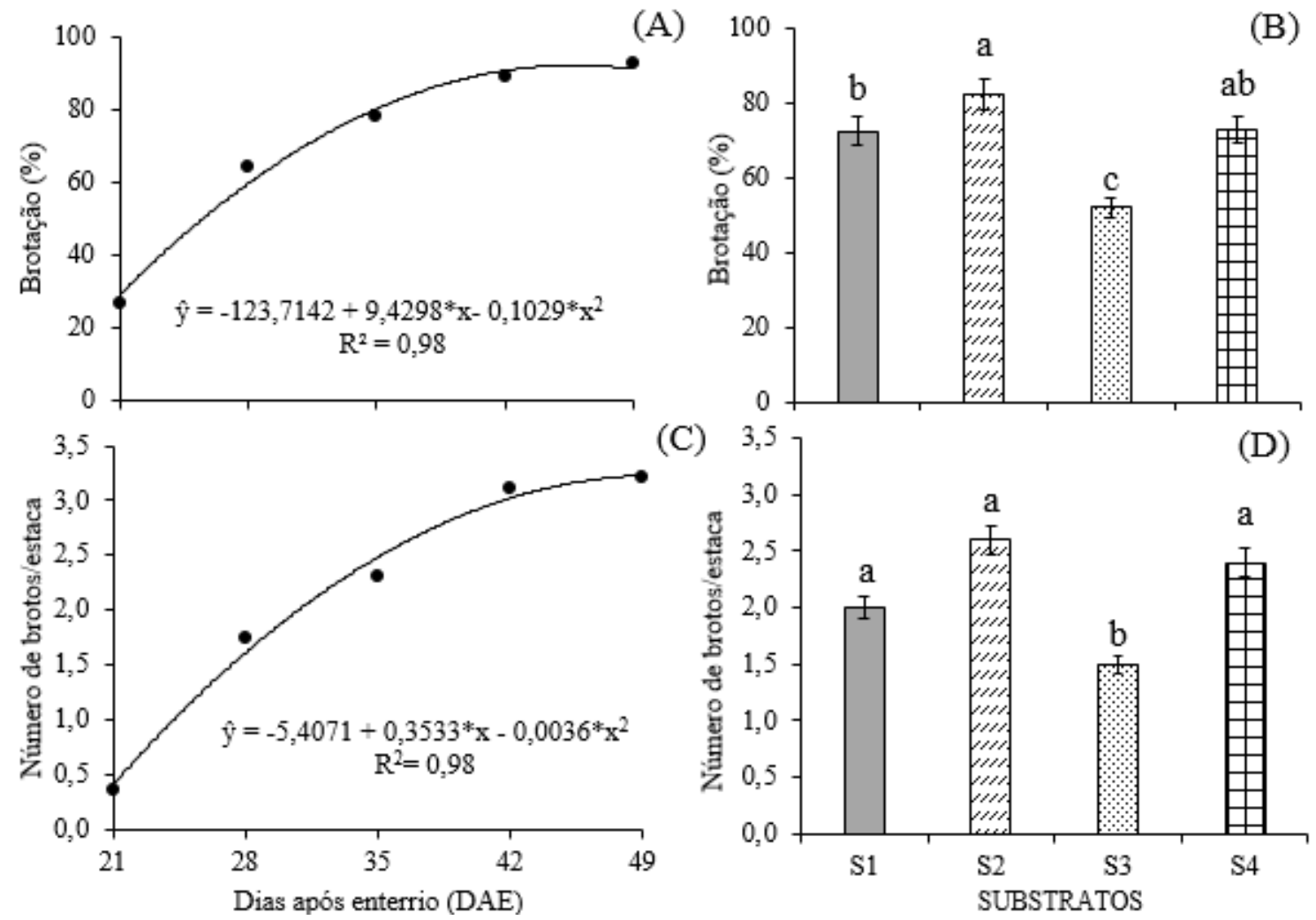

Figura 1. Brotação $(A, B)$, número de brotos por estaca $(C, D)$ em mudas de $P$. aculeata produzidas em

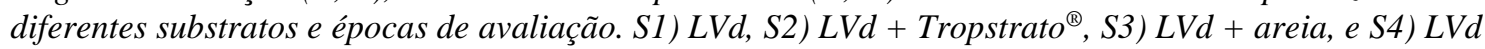
+ cama de frango. Letras iguais, não diferem entre si, pelo teste de Tukey $(p>0,05)$. * $(p<0,05)$.

Os maiores resultados de brotação e número de brotos aos 46-49 dias são esperados devido ao aumento da divisão celular das gemas em função das reservas contidas na estaca. Após esse período, geralmente, os processos de multiplicação tendem a estabilizar-se. Quanto aos substratos, os resultados estão associados a participação dos nutrientes presentes no substrato comercial e cama de frango na composição do substrato, especialmente o nitrogênio, que contribui no desenvolvimento vegetativo [18]. De maneira semelhante, Cunha et al. (2015) [19] avaliando a propagação vegetativa por estaquia de Piper hispidum Sw., em diferentes substratos, observaram maiores características de brotações em solo + cama de frango. 
Os substratos não influenciaram o enraizamento das estacas, comprimento de raízes, área radicular, massa fresca das raízes, número de folhas e o índice de clorofila, com médias gerais de $92 \%, 14,0 \mathrm{~cm}, 12,25 \mathrm{~cm}^{2}$ e 0,7075 g, 5,07 folhas/estaca e 34,6 SPAD, respectivamente.

Este fato pode ser justificado devido ao fácil enraizamento da espécie, por apresentar rizogênese direta [20]. Resultados similares foram descritos por Higa et al. (2012) [21] que constataram enraizamento médio de $91 \%$ em mudas de P. aculeata, independente dos substratos estudados.

As maiores áreas foliares ocorreram nas mudas produzidas nos substratos $\mathrm{LVd}, \mathrm{LVd}+$ Tropstrato $^{\circledR}$ e LVd + cama de frango (S1, S2 e S4, respectivamente), diferindo-se estatisticamente apenas daquelas em LVd + areia (S3) (Figura 2A). A avaliação da área foliar contribui na compreensão da otimização e aproveitamento luminoso, uma vez que, está característica está associada a capacidade de interceptação da radiação solar incidente [22], e quanto maior for o valor, sugere-se que há maior produção e distribuição de fotoassimilados, favorecendo o desenvolvimento das mudas.
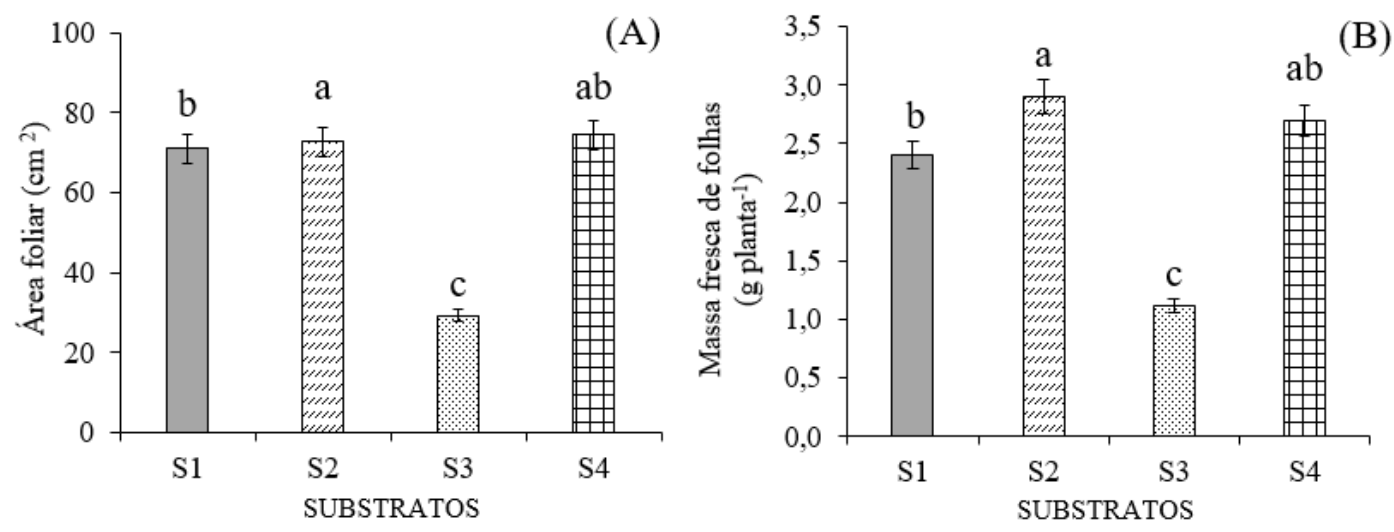

Figura 2. Área foliar (A) e massa fresca de folhas $(B)$ em mudas de P. aculeata produzidas em diferentes substratos. S1) $L V d$, S2) $L V d+$ Tropstrato $\left.^{\circledR}, S 3\right) L V d+$ areia, e S4) $L V d+$ cama de frango. Letras iguais, não diferem entre si, pelo teste de Tukey $(p>0,05)$.

As maiores AF devem-se à elevada capacidade de troca de cátions, do LVd (testemunha) quanto do substrato comercial (Tabela 1), bem como benefícios da baixa relação $\mathrm{C} / \mathrm{N}(10,87)$ e alto teor de matéria orgânica $\left(447,0 \mathrm{~g} \mathrm{~kg}^{-1}\right)$ da cama de frango, de acordo análise química do resíduo, contribuindo em rápida decomposição e mineralização, favorecendo a disponibilidade de nutrientes para as mudas.

As maiores produções de massas frescas de folhas ocorreram na presença de LVd + Tropstrato ${ }^{\circledR}$ e LVd + cama de frango (Figura 2B), superando em 160,7 \% e 141,9 \%, quando comparada as de menor valor $(1,12 \mathrm{~g})$, em $\mathrm{LVd}+$ areia. O resultado positivo do substrato $\mathrm{LVd}+$ Tropstrato $^{\circledR}$ na produção de massa de folhas deve-se provavelmente ao elevado teor de fósforo pelo fato do substrato comercial conter em sua composição o superfosfato simples. O fósforo auxilia nos processos fotoquímicos e bioquímicos da fotossíntese, potencializando a produção de biomassa [23]. Quanto ao uso do resíduo orgânico, Guimarães (2015) [24] realizou o cultivo de P. aculeata sob condições de campo e observando que a adição de resíduos orgânicos também influenciou positivamente a produção de folhas.

Os menores valores tanto de AF quanto massa fresca de folhas ocorreram na presença de areia e LVd. Este resultado pode ser explicado pelo fato de que a areia utilizada é considerado praticamente material inerte, ou seja, pouco afeta as características químicas do substrato; consequentemente menor disponibilidade de nutrientes, alocação e produção de biomassa.

A taxa de assimilação de $\mathrm{CO}_{2}(A)$, transpiração $(E)$, condutância estomática $(g s)$, eficiência instantânea de carboxilação da Rubisco $\left(A / C_{\mathrm{i}}\right)$ e concentração intercelular de $\mathrm{CO}_{2}\left(C_{\mathrm{i}}\right)$ foram influenciadas pelos substratos. Em geral, constatou-se que os maiores valores, exceto para $C_{\mathrm{i}}$, ocorreram nas mudas produzidas em LVd + cama de frango (Figura 3). Já, a WUE não foi

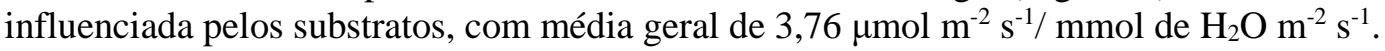



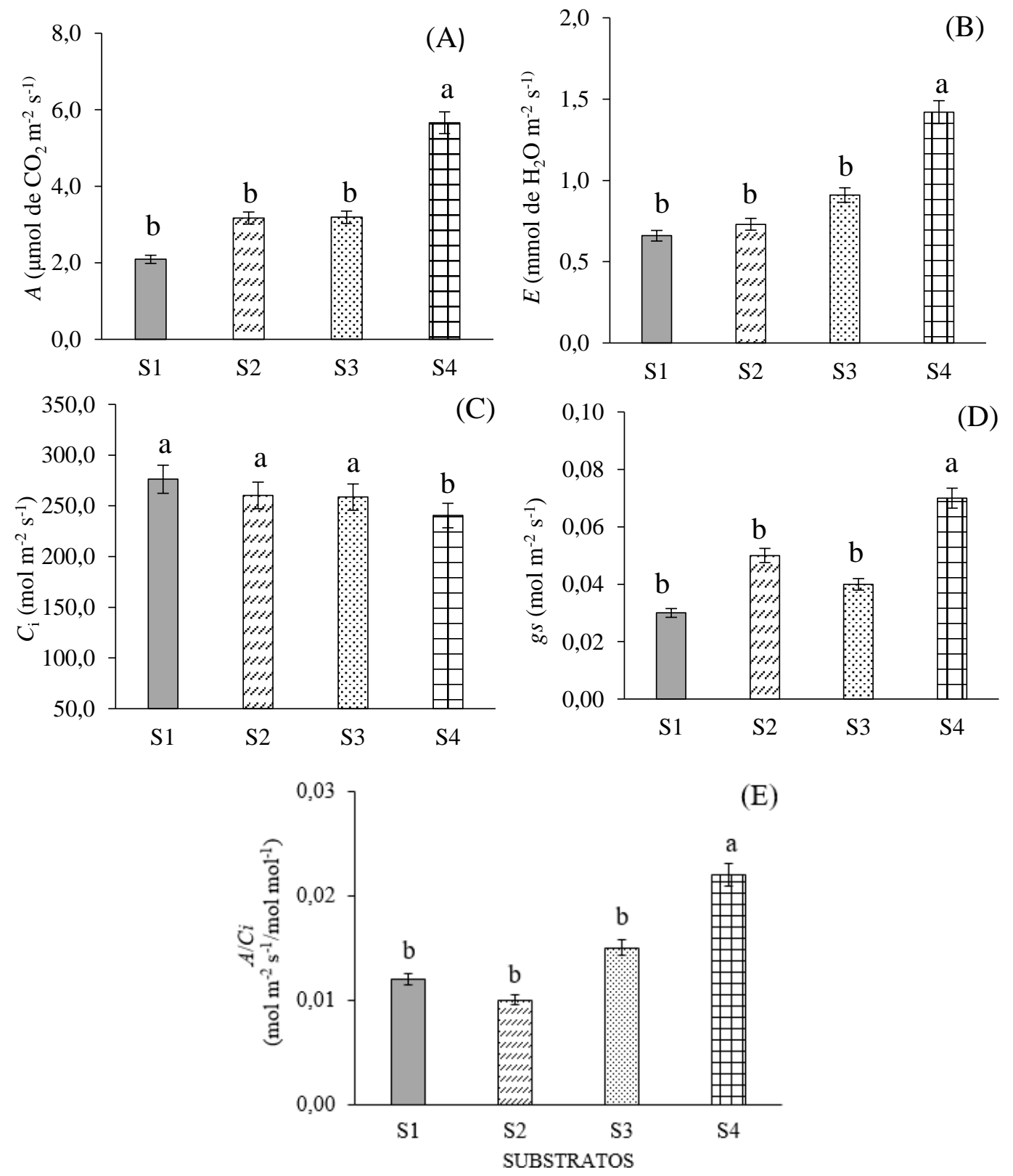

(E)

Figura 3. Taxa de assimilação de $\mathrm{CO}_{2}-A(A)$, transpiração - $E(B)$, concentração intercelular de $\mathrm{CO}_{2}-C_{\mathrm{i}}$ (C) condutância estomática - gs (D) e eficiência de carboxilação da Rubisco - $A / C_{\mathrm{i}}(E)$ em folhas de mudas

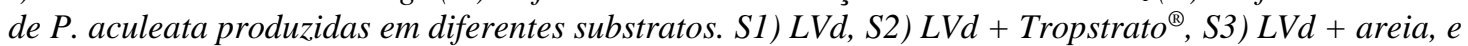
S4) $L V d+$ cama de frango. Letras iguais, não diferem entre si, pelo teste de Tukey ( $p>0,05)$.

Em geral, as maiores trocas gasosas nas mudas produzidas no substrato com adição de cama de frango devem-se provavelmente ao incremento de nutrientes presentes no resíduo orgânico. A cama de frango apresenta elevado aporte de nutrientes [25], principalmente nitrogênio $\left(23,90 \mathrm{~g} \mathrm{~kg}^{-1}\right)$. O nitrogênio faz parte da molécula da clorofila e aminoácidos associado à ribulose 1,5-bifosfato carboxilase oxigenase (Rubisco) [26]. Além disso, a adição desse material ao solo pode ter contribuído na redução da densidade do substrato de cultivo, acarretando em melhorias de contato das raízes com os nutrientes, contribuindo na nutrição das mudas.

A menor $C_{\mathrm{i}}$ nas mudas produzidas em $\mathrm{LVd}+$ cama de frango deve-se à maior eficiência de carboxilação da Rubisco $\left(A / C_{\mathrm{i}}\right)$ nesse mesmo substrato, o que resultou na potencialização da assimilação de $\mathrm{CO}_{2}(A)$. Neste sentido, as trocas gasosas favorecem a produção de fotoassimilados a serem utilizados no desenvolvimento vegetativo e formação das mudas. Esses resultados estão associados ao incremento de nutrientes devido à adição da cama de frango ao substrato de cultivo, 
com a consequente melhoria dos atributos químicos, devido ao aumento da matéria orgânica [27], favorecendo a atividade fotossintética das mudas.

Dentre os nutrientes presentes na cama de frango, destacam-se o nitrogênio, fósforo e enxofre $\left(23,90 ; 15,36\right.$ e $18,65 \mathrm{~g} \mathrm{~kg}^{-1}$, respectivamente). O nitrogênio está interligado a bases dos nucleotídeos e dos aminoácidos da Rubisco [28]. O fósforo está associado a redução de trioses fosfato usadas durante a regeneração da Rubisco e produção de adenosina trifosfato (ATP) e fosfato de dinucleotídeo de adenina e nicotinamida (NADPH) [29], e o enxofre faz parte da ferrodoxina, contribuindo no transporte de elétrons e funções metabólicas [30], assegurando o metabolismo fotossintético.

Constatou-se maior gs nas mudas produzidas em LVd + cama de frango, possivelmente em função da maior $E$, isto é, os estômatos tendem a abrir os poros estomáticos aumentando assim a condutância. A redução dessas características fisiológicas nas mudas com os demais substratos devem-se as condições limitantes, tais como elevada densidade de partícula em LVd, alta porosidade e saturação por bases no substrato comercial, e baixo aporte de nutrientes na areia, fazendo com que reduza a capacidade de assimilação de $\mathrm{CO}_{2}$, comprometendo os processos bioquímicos da fotossíntese nas mudas de $P$. aculeata. Desta forma, o uso de resíduos orgânicos para produção de mudas, além de contribuir no aporte de nutrientes, favorece aumento de área de exploração radicular com a rizosfera, sendo uma prática agronômica sustentável recomendada.

Entretanto, as respostas fisiológicas variam de acordo com as espécies. Alves et al. (2016) [30], avaliando as trocas gasosas em mudas de Coffea canephora em diferentes substratos, verificaram que os substratos não afetaram as características de trocas gasosas, exceto $E$, que foi maior nas mudas produzidas em substrato constituído por resíduos orgânicos. Por outro lado, Sá et al. (2016) [31] observaram que todas as características associadas ao metabolismo fotossintético foram influenciadas por diferentes substratos, em que a menor capacidade fotossintética ocorreu em mudas de Carica papaya L. com substrato sem adição de resíduos orgânicos (Neossolo Fúlvico + areia).

\section{CONCLUSÃO}

O Tropstrato ${ }^{\circledR}$ e a cama de frango são materiais a serem utilizados na formulação de substratos para Pereskia aculeata, pela maior capacidade vegetativa e fotossintética das mudas.

\section{AGRADECIMENTOS}

A CAPES e CNPq, pela concessão das bolsas, e à FUNDECT, pelo apoio financeiro.

\section{REFERÊNCIAS BIBLIOGRÁFICAS}

1. Queiroz CRAA, Ferreira L, Paiva Gomes LB, Melo CMT, Andrade RR. Ora-pro-nóbis em uso alimentar humano: percepção sensorial. Rev Verde de Agroec Desenv Sust. 2015;10(3):1-5. doi: 10.18378/rvads.v10i3.3393

2. Duarte MR, Hayashi SS. Estudo anatômico de folha e caule de Pereskia aculeata Mill. (Cactaceae). Rev Bras Farmacognosia. 2005;15(2):103-109. doi: 10.1590/S0102-695X2005000200006

3. Fidélix MP, Pereira CAM, Pulitano VMSE. Estudo experimental sobre as características nutricionais e sensoriais do ora-pro-nóbis (Pereskia aculeata Mill). Nutrição Brasil. 2010;9(6):392- 397.

4. Dias ACP, Pinto NAVD, Yamada LTP, Mendes KL, Fernandes AG. Avaliação do consumo de hortaliças não convencionais pelos usuários das Unidades do Programa Saúde da Família (PSF) de Diamantina MG. Alimentos e Nutrição. 2005;16(3):279-284.

5. Takeiti CY, Antonio GC, Motta EM, Collares-Queiroz FP, Park KJ. Nutritive evaluation of nonconventional leafy vegetable (Pereskia aculeata Miller). Int J Food Sci Nutr. 2009,60(1):148- 160. doi: $10.1080 / 09637480802534509$

6. Barros KN, Guimarães HET, Sartor CFP, Felipe FD, Amaral V, Cortez LEL. Desenvolvimento de formulação de uso tópico com ação cicatrizante contendo extrato de Pereskia aculeata. Iniciação Científica CESUMAR. 2010;12(1):29-37. doi: 10.17765/1518-1243.2010v12n1p\%25p

7. Sartor CFP, Amaral V, Guimarães HET, Barros KN, Felipe DF, Cortez LER, Veltrini VC. Estudo da ação cicatrizante das folhas de Pereskia aculeata. Rev Saúde Pesq. 2010;3(2):149-154. 
8. Hartmann HT, Kester DE, Davies FT, Geneve R. Plant propagation: principles e practices. 8. ed. Boston: Prentice Hall, 2011, 915p.

9. Domingues TF, Meir P, Feldpausch TR, Saiz G, Veenendaal EM, Schrodt F, Beid M, Djagbletey G, Hien F, Campaore H, Diallo A, Grace J, Lloyd J. Co-limitation of photosynthetic capacity by nitrogen and phosphorus in West capacity by nitrogen and phosphorus in West Africa Woodlands. Plant Cell and Environment. 2010;33(6):959-980. doi: 10.1111/j.1365-3040.2010.02119.x

10. Araújo WBM, Alencar RD, Mendonça V, Medeiros EV, Carvalho Andrade R, Araújo RR. Esterco caprino na composição de substratos para formação de mudas de mamoeiro. Ciênc Agrotec. 2010;34(1): 68-73. doi: 10.1590/S1413-70542010000100008

11. Vukobratović M, Lončarić Z, Vukobratović Ž, Mužić M. Use of composted manure as substrate for lettuce and cucumber seedlings. Waste and Biomass Valorization 2018;9(1):25-31. doi: 10.1007/s12649016-9755-2

12. Lima RLS, Severino LS, Silva MIL, Jerônimo JF, Vale LS, Beltrão NEM. Substratos para produção de mudas de mamoneira compostos por misturas de cinco fontes de matéria orgânica. Ciênc Agrotec. 2006;30(3):474-479. doi: 10.1590/S1413-70542006000300013

13. Alvares CL, Stape JL, Sentelhas PC, Gonçalves JLM, Sparovek G. Köppen's climate classification map for Brazil. Meteorol Zeitschrift. 2013;22(6):711-728. doi: 10.1127/0941-2948/2013/0507

14. Santos HG, Jacomine PKT, Anjos LHC, Oliveira VA, Lumbreras JF, Coelho MR, Almeida JA, Cunha T. JF, Oliveira JB. Sistema brasileiro de classificação de solos. 3. ed. Rio de Janeiro: Embrapa Solos, 2013, 306p.

15. Silva FC. Manual de análises químicas de solos, plantas e fertilizantes. 2 ed. Brasilia, DF: Embrapa informação tecnológica, 2009, 627 p.

16. Maguire JD. Speed of germination aid in selection and evaluation for seedling emergence and vigor. Crop Sci. 1962;2:176-177.

17. Ferreira DF. Sisvar: a guide for its bootstrap procedures in multiple comparisons. Ciên Agrotec. 2014;38(2): 109-112. doi: 10.1590/S1413-70542014000200001

18. Trazzi PA, Caldeira MVW, Passos RR, Gonçalves EO. Substratos de origem orgânica para produção de mudas de teca (Tectona grandis Linn. F.). Ciênc Fl. 2013;23(3):401-409. doi: 10.5902/1980509810551

19. Cunha ALB, Chaves FCM, Batista AC, Hidalgo AF. Propagação vegetativa de estacas de Piper hispidum Sw. em diferentes substratos. Rev Bras Plantas Med. 2015;17(4):685-692. doi: 10.1590/1983084X/14_113

20. Zem LM, Zuffellato-Ribas KC, Koehler HS. Enraizamento de estacas semilenhosas de Pereskia aculeata nas quatro estações do ano em diferentes substratos. Rev Eletrôn Cient UERGS. 2016;2(3):227233. doi: $10.21674 / 2448-0479.23 .227-233$

21. Higa KM, Fior CS, Rodrigues LR. Ensaios para a propagação in vivo e in vitro de ora-pro-nóbis (Pereskia aculeata). Pesq Agropecu Gaúcha. 2012;18(1):59-66.

22. Spann TM, Heerema RJ. A simple method for non-destructive estimation of total shoot leaf area in tree fruit crops. Sci Horticulturae. 2010;125(3):528-533. https://doi.org/10.1016/j.scienta.2010.04.033

23. Silva EP, Gomes VFF, Mendes Filho PF, Silva Júnior JMT, Ness RL. Desenvolvimento e colonização micorrízica em mudas de embaúba adubadas com fosfato natural e material orgânico. Rev Ciênc Agron. 2016;47(2):256-263. doi: 10.5935/1806-6690.20160030

24. Guimarães JRA. Produtividade e características físico-químicas de ora-pro-nóbis sob adubação orgânica. 2015. 59 f. Dissertação (Mestrado em Horticultura) - Universidade Estadual Paulista Júlio de Mesquita Filho, Botucatu.

25. Bolan N, Szogi A, Chuasavathi T, Seshadri B, Rothrock M, Panneerselvam P. Uses and management of poultry litter. World's Poultry Sci J. 2010;66(4):673-698. doi: 10.1017/S0043933910000656

26. Taiz L, Zeiger E, Møller IM, Murphy, A. Fisiologia e Desenvolvimento Vegetal. 6. ed. Porto Alegre: Artmed, 2017, $888 \mathrm{p}$.

27. Orrico Junior MAP, Orrico ACA, Lucas Junior J. Biodigestão anaeróbia dos resíduos da produção avícola: cama de frangos e carcaças. Eng Agríc. 2010;30(3):546-554. doi: 10.1590/S010069162010000300018

28. Vieira DP, Portes TA, Seraphin ES, Teixeira JB. Fluorescência e teores de clorofila em abacaxizeiro cv. perola submetido a diferentes concentrações de sulfato de amônio. Rev Bras Frutic. 2010;32(2):360-368. doi: 10.1590/S0100-29452010005000061

29. Domingues TF, Meir P, Feldpausch TR, Saiz G, Veenendaal EM, Schrodt F, Beid M, Djagbletey G, Hien F, Campaore H, Diallo A, Grace J, Lloyd J. Co-limitation of photosynthetic capacity by nitrogen and phosphorus in West capacity by nitrogen and phosphorus in West Africa Woodlands. Plant Cell and Environment. 2010;33(6):959-980. doi: 10.1111/j.1365-3040.2010.02119.x

30. Alves ER, Schmidt R, Moreira R, Dias JRM, Maia E. Biometria e trocas gasosas em mudas clonais de cafeeiro submetidas a diferentes substratos. Coffee Sci. 2016;11(4):435-443. doi: 10.25186/cs.v11i4.1110 
31. Sá FVS, Brito MEB, Silva LA, Cavalcante LF, Moreira RCL, Figueiredo LC, Paiva EP. Growth and gas exchanges of papaya tree seedlings grown on alternative substrates. Científica. 2016;44(2):245-254. doi: $10.15361 / 1984-5529.2016 \mathrm{v} 44 \mathrm{n} 2 \mathrm{p} 245-254$ 